\title{
Diving beetle (Coleoptera: Dytiscidae) community dissimilarity reveals how low landscape connectivity restricts the ecological value of urban ponds
}

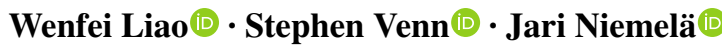

Received: 9 March 2021 / Accepted: 27 January 2022 / Published online: 12 February 2022

(C) The Author(s) 2022

\begin{abstract}
Context Structural and functional connectivity, as subconcepts of landscape connectivity, are key factors in biodiversity conservation and management. Previous studies have focused on the consequences of connectivity for populations of terrestrial organisms, which may not be appropriate for aquatic organisms.

Objectives As landscape connectivity critically affects the potential value of ponds for biodiversity, here we used diving beetles (Dytiscidae), an indicator taxon of wetland biodiversity, to investigate how structural connectivity affects functional connectivity to aquatic invertebrates in an urban landscape.

Methods We assessed pairwise similarities of dytiscid community, i.e. the variation of species composition between clustered and isolated ponds in the Helsinki Metropolitan Area, Finland. We investigated how dytiscid community similarity is affected by
\end{abstract}

Supplementary Information The online version contains supplementary material available at https://doi. org/10.1007/s10980-022-01413-z.

W. Liao $(\bowtie) \cdot$ S. Venn $\cdot$ J. Niemelä

Faculty of Biological and Environmental Sciences, University of Helsinki, P.O. Box 65, 00014 Helsinki, Finland

e-mail: wenfei.liao@helsinki.fi

S. Venn

Department ofInvertebrate Zoology \& Hydrobiology, Faculty of Biology \& Environmental Protection, University ofLodz, Banacha 12/16, 90-237, Lodz, Poland
Euclidean distances between ponds, as an indicator of structural connectivity.

Results We found that clustered ponds shared more species than isolated ponds. Dytiscid species community similarity responded negatively to increasing Euclidean distance between ponds. Effectively dispersing species were widely distributed across the landscape, while poor dispersers were scarcely distributed in the same landscape.

Conclusions Structural connectivity determines which species are able to disperse successfully, with poor dispersers restricted to well-connected ponds. The different responses of effective dispersers and poor dispersers to the same structural connectivity indicate that functional connectivity determines species composition. We recommend providing wellconnected aquatic habitats in urban landscapes and the implementation of measures to reduce isolation of wetland assemblages. Even clustered ponds need dispersal from other habitats to ensure their contribution to urban biodiversity.

Keywords Aquatic insect $\cdot$ Flight capacity $\cdot$ Habitat connectivity $\cdot$ Habitat isolation $\cdot$ Macroinvertebrate . Urban blue infrastructure

\section{Introduction}

Landscape connectivity refers to "the degree to which the landscape facilitates or impedes movement among 
resource patches" (Taylor et al. 1993). Structural connectivity and functional connectivity are subconcepts within the topic of landscape connectivity. Structural connectivity refers to the physical structure of the landscape, such as the spatial relationship between habitat patches, while functional connectivity accounts for behavioural responses of organisms to the landscape structure (Taylor et al. 2006). In urban contexts, landscapes are highly fragmented and vulnerable to habitat loss, consequently resulting in decreasing structural connectivity and increasing isolation of habitats (Concepción et al. 2015). Impermeable surfaces and structures, such as buildings and roads, constitute ecological traps and movement barriers, obstructing the dispersal of organisms and thereby decreasing functional connectivity of habitats (Horváth et al. 2009; Muñoz et al. 2015). Most research about structural and functional connectivity has focused on organisms in terrestrial ecosystems, which can differ considerably from the needs of aquatic organisms (Pringle 2006; Villalobos-Jimenez et al. 2016).

Urban ponds are crucial components of urban green-blue infrastructure, providing essential habitats to support biodiversity (Hill et al. 2017). They harbour a wide range of organisms, including macrophytes (e.g. Gledhill et al. 2008), invertebrates (e.g. Liao et al. 2020), amphibians (e.g. Mazgajska 1996), and waterbirds (e.g. Murray et al. 2013). Although urban ponds are discrete and often surrounded by inhospitable terrestrial landscapes, they can be functionally connected if species can cross the intervening habitat matrices and disperse between ponds (Tischendor and Fahrig 2000). Previous research has shown that structural connectivity can increase functional connectivity for aquatic taxa that disperse via terrestrial routes, such as amphibians (e.g. Ribeiro et al. 2011) and aquatic reptiles (e.g. Pereira et al. 2011). Structural connectivity, however, is not the only factor determining functional connectivity (Taylor et al. 2006) and affecting species distributions.

As functional connectivity accounts for behavioural responses of organisms to environmental changes in landscapes, changes in habitat-specific environmental factors can affect the dispersal of organisms and species distribution. Habitat quality affects the dispersal of organisms (Clobert et al. 2009) and their potential to colonize new habitats (Moilanen and Hanski 1998). In aquatic ecosystems, predator-prey dynamics affect species survival (e.g. Goertzen and Suhling 2013; Liao et al. 2020), which also affects the potential of dispersing individuals to establish a new population. As habitats are not uniform in quality (Moilanen and Hanski 1998), it is necessary to consider habitat-specific environmental factors when we investigate functional connectivity.

Previous research on the effects of landscape connectivity on the movement of aquatic taxa between habitats has mainly focused on organisms dispersing via terrestrial routes (e.g. Ribeiro et al. 2011; Pereira et al. 2011). Little knowledge is available on the effects of landscape connectivity on aquatic organisms that use aerial dispersal. To enhance the capacity of urban blue infrastructure to support biodiversity, it is crucial to understand how landscape connectivity affects taxa with different dispersal capacity, so that we can generate reliable recommendations for conservation planning and the design of urban blue infrastructure.

In this study, we use diving beetles (Dytiscidae) as a study taxon. Dytiscids are a family of aquatic insects, in which most species disperse primarily using aerial flight (Nilsson and Holmen 1995). The flight capacity of dytiscids varies among species; most species are active fliers, while some species have poor flight capacity with absent or variable flight musculature (Jackson 1952, 1956a, 1956b, 1972; Kehl and Dettner 2007). Such variation in flight capacity in dytiscids may be related to different levels of investment of energy in dispersal and reproduction (Bilton 2014). Dytiscids have been recommended as an indicator taxon for rapid assessment of pond biodiversity (Bilton et al. 2006; Becerra-Jurado et al. 2014), but their diversity depends on both pond quality and landscape connectivity (Iversen et al. 2013, 2017). Here, we use community similarity/dissimilarity, i.e. the variation in species composition, to investigate the responses of dytiscids to habitat isolation. Specifically, we aim to answer the following questions: (1) How does structural connectivity affect dytiscid community dissimilarity between urban wetlands? (2) Do clustered ponds have better functional connectivity for dytiscids than isolated ponds? Finally, we consider the presence or absence of fish as a habitat-specific factor for dytiscid population persistence (Goertzen and Suhling 2013; Liao et al. 2020) to address (3) How does the presence/absence of fish affect dytiscid community dissimilarity? 


\section{Methods}

Study site and data collecting

We surveyed 26 urban ponds at 11 sites in the Helsinki Metropolitan Area, Finland $\left(60.1699^{\circ} \mathrm{N}\right.$, $24.9384^{\circ}$ E; Fig. 1). Six ponds (I1-I6) were isolated, with at least $1 \mathrm{~km}$ distance to other ponds, while the other 20 ponds comprise five groups ( $2-8$ ponds per site). Fifteen ponds were fishless, and eleven ponds had fish (Fig. 1). Some ponds, such as the ponds at site $\mathrm{G} 4$, were formed due to sand extraction in areas with abundant groundwater. The fish in some of the ponds were introduced by local residents for recreational purposes (Liao 2017). The pond sizes varied from 0.013 to 1.18 hectare (mean $=0.27 \pm 0.32$ hectare), with shoreline perimeter of $59-559 \mathrm{~m}$ (mean $=210 \pm 132 \mathrm{~m})$.

We operated 1-L activity traps horizontally in the water for $48 \mathrm{~h}$ (Elmberg et al. 1992) in May and July
2017-2019. We did not use bait in activity traps, in order to avoid sample bias caused by bait effects. The number of traps set in each pond was determined according to the available shoreline length during the trapping period (see Liao et al. 2020). We use activity traps to sample dytiscids instead of handnet sweeping in our urban ponds to avoid destruction in vegetation caused by handnetting and reduction in the aesthetic appearance of urban ponds. The dytiscid specimens were preserved in $70 \%$ ethanol until identification. We identified the specimens to the species level according to Nilsson and Holmen (1995) and followed the nomenclature of Nilsson and Hájek (2021). We also operated a fish trap for $24 \mathrm{~h}$ in each permanent pond, to determine the presence or absence of fish. We estimated the Euclidean distance between ponds using The City of Helsinki Map Service (2019), as an indicator of structural connectivity between ponds (Kindlmann and Burel 2008).

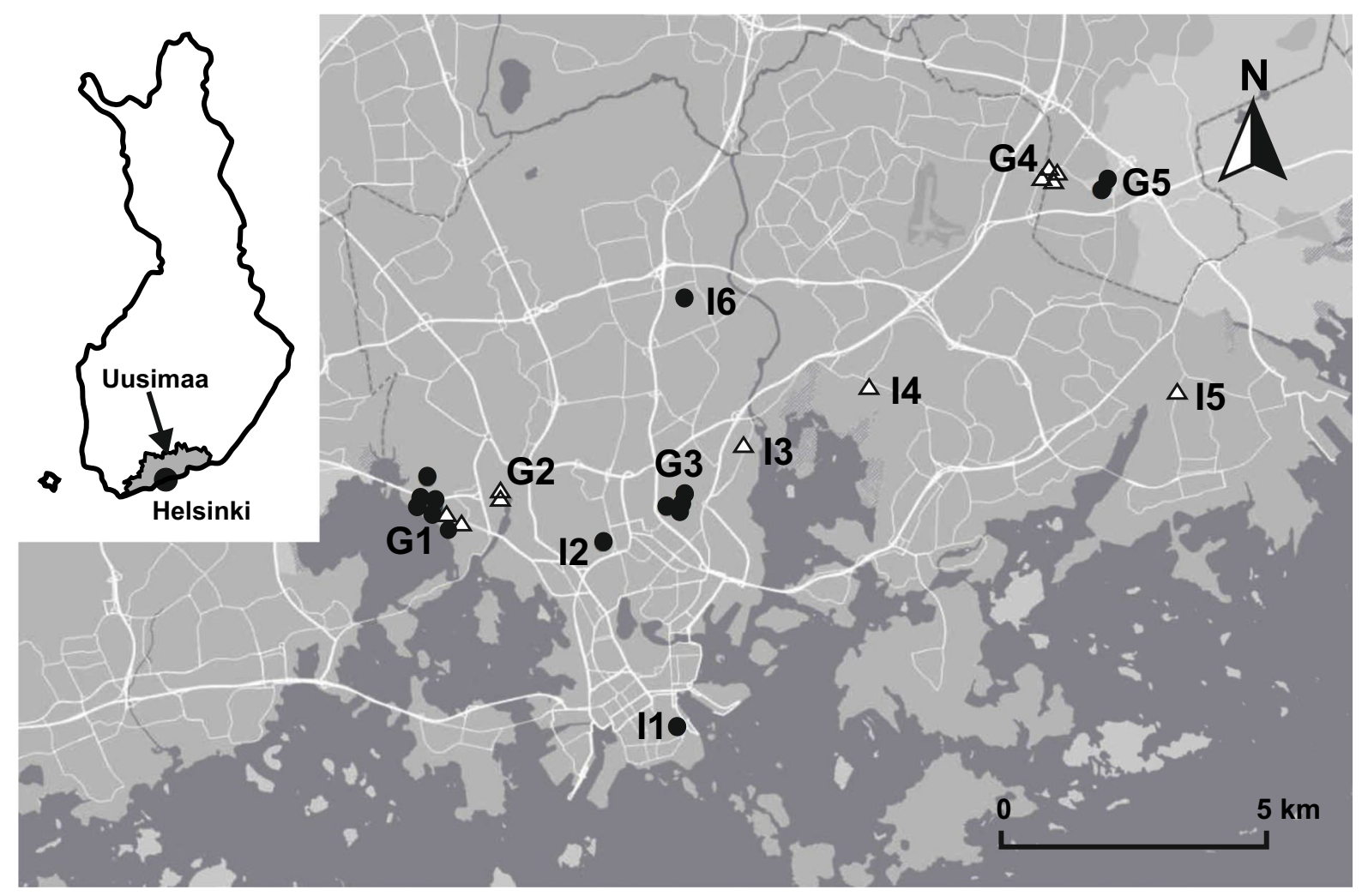

Fig. 1 Map of study ponds in the Helsinki Metropolitan Area $\left(60.1699^{\circ} \mathrm{N}, 24.9384^{\circ} \mathrm{E}\right)$, Finland. Open triangles represent ponds with fish, while filled dots represent fishless ponds. The ponds are located at 11 sites. Sites labelled with 'I' are isolated ponds, and sites labelled with ' $G$ ' are ponds in groups 
Statistical analysis

We applied the function "hclust" in the "vegan" package (Oksanen et al. 2019) to perform hierarchical clustering with average linkage in $\mathrm{R}$ software (version 3.6.3, R Core Team 2020). We conducted hierarchical clustering with the presence or absence of all recorded species during the three years (Online Appendices 2 and 3), to investigate the similarities between isolated ponds and clustered ponds. Twenty-four ponds at the 11 sites were included in the analysis; two ponds were excluded from the analysis because no beetle was caught during the three sampling years. Furthermore, we applied the hierarchical clustering with the species that occurred in at least two out of the three sampling years in a pond (Online Appendix 2), to investigate how differently isolated ponds and ponds in groups support dytiscids. A total of nineteen ponds at eight sites were included in this analysis.

To compare dytiscid assemblages between ponds with different Euclidean distances, we first applied the function "vegdist", in the "vegan" package, to obtain Jaccard pairwise dissimilarity index values between ponds from the dytiscid presence/absence data. The Jaccard index values varied between 0 and 1 , with 0 meaning the species compositions are the same, and 1 meaning the species compositions are totally different. Next, we used the "glmmTMB" package (Brooks et al. 2017) to fit generalised linear models (GLM) with a beta distribution (Smithson and Verkuilen 2006). To avoid zeros and ones in the response variable, we rescaled the dissimilarity values to lie within the interval $(0,1)$, according to Smithson and Verkuilen (2006). As the presence of fish affects dytiscid species composition (Liao et al. 2020), we considered the presence or absence of fish in our data analyses. In the GLMs, covariates included the Euclidean distances between ponds, the presence/absence of fish in each pair of ponds in the semi-matrix, i.e. "fish in neither", "fish in one but not the other", and "fish in both", and these variables in interaction. The full model is described in Online Appendix 1 and we used the function "drop1" to select the optimal model, based on the lowest Akaike information criterion (AIC) values (Zuur and Ieno 2016).

\section{Results}

In total, we recorded 60 dytiscid species in the 26 study ponds. Thirty species occurred in at least one of the ponds during two out of the three sampling years (Online Appendix 2), while the other 30 species were recorded in only one of the sampling years (Online Appendix 3). The fish species recorded in this study were crucian carp (Carassius carassius), Prussian carp (C. gibelio), tench (Tinca tinca), European perch (Perca fluviatilis), northern pike (Esox lucius), and three-spined stickleback (Gasterosteus aculeatus).

Our hierarchical clusters showed that ponds within a site share more dytiscid species than ponds at different sites, but the presence of fish can lead to high dissimilarities between ponds within the same site (Fig. 2a). Ponds with fish were less likely to have dytiscids than ponds without fish. Only 6 out of 11 ponds with fish supported at least one dytiscid species, and these species include Cybister lateralimarginalis and Dytiscus marginalis (Fig. 2b \& Online Appendix 2). By contrast, 13 out of 15 ponds without fish supported dytiscids (Fig. 2b). Clustered ponds supported certain numbers of dytiscid species, while isolated ponds without fish shared similar species composition with ponds at other sites (Fig. 2b; Online Appendix 2). Poor disperser species, such as Hyphydrus ovatus and Graphoderus spp., had a greater probability of occurrence in clustered ponds (Online Appendix 2).

The GLM result shows that the community dissimilarity index increased with increasing Euclidean distance between two ponds (p-value $<0.001$, Fig. 3a-c; Online Appendix 1). However, there is also considerable variation between the assemblages of adjacent ponds (community dissimilarity index $0.2-1.0$ ). With the pond combination "both fishless" as reference, the other two pond combinations had larger positive effects on the community dissimilarity indices than the Euclidean distances between ponds (Online Appendix 1). Community dissimilarity index was significantly lower between the combination of two fishless ponds $(0.69 \pm 0.19)$ than between a fishless pond and a pond with fish $(0.79 \pm 0.19$, p-value $<0.001)$, and between two ponds with fish $(0.77 \pm 0.24$, p-value $<0.001)$. The combination of a fishless pond and a pond with fish had no significant difference in community dissimilarity indices compared to the 


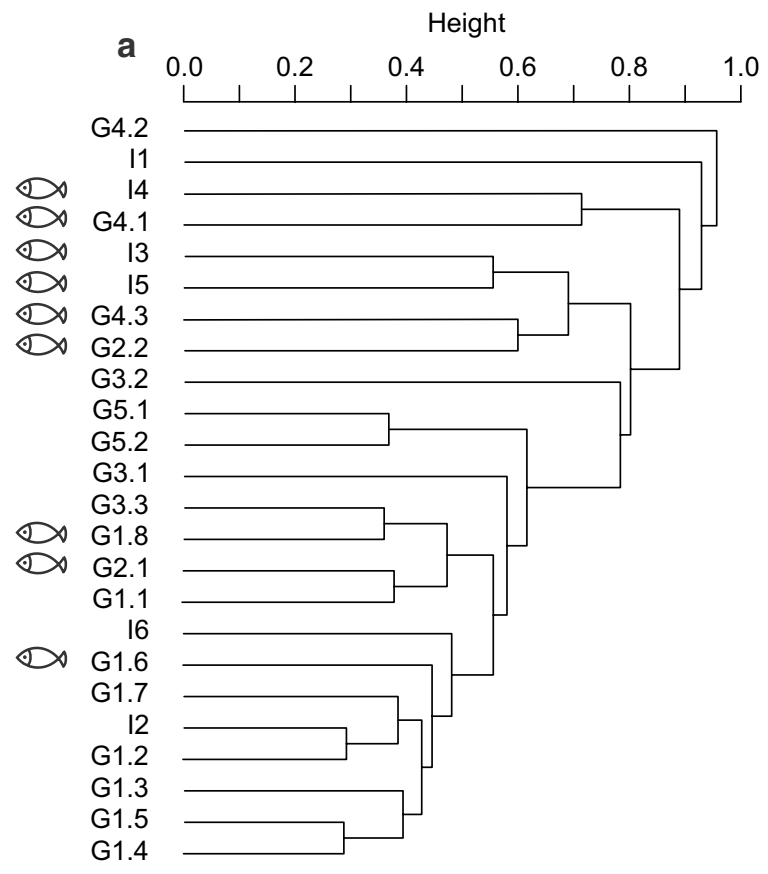

Fig. 2 Cluster analysis of pond dytiscid species similarities: a all dytiscid species occurred during the sampling years are included in the analysis; $\mathbf{b}$ species that occurred during at least two out of the three sampling years, were included in the

combination of two ponds with fish (p-value $=0.553$, Fig. 3d).

\section{Discussion}

In this study, we investigated how structural connectivity between urban ponds affects the community similarity of dytiscids, and how the presence/absence of fish affects dytiscid species similarity between ponds in the landscape. We found that dytiscid community dissimilarity increases with decreasing structural connectivity between urban ponds. Ponds close to other ponds generally share more species and thus have higher functional connectivity than isolated ponds. The presence of fish, however, can make ponds functionally disconnected to most dytiscid species, even though they are located close to other ponds.

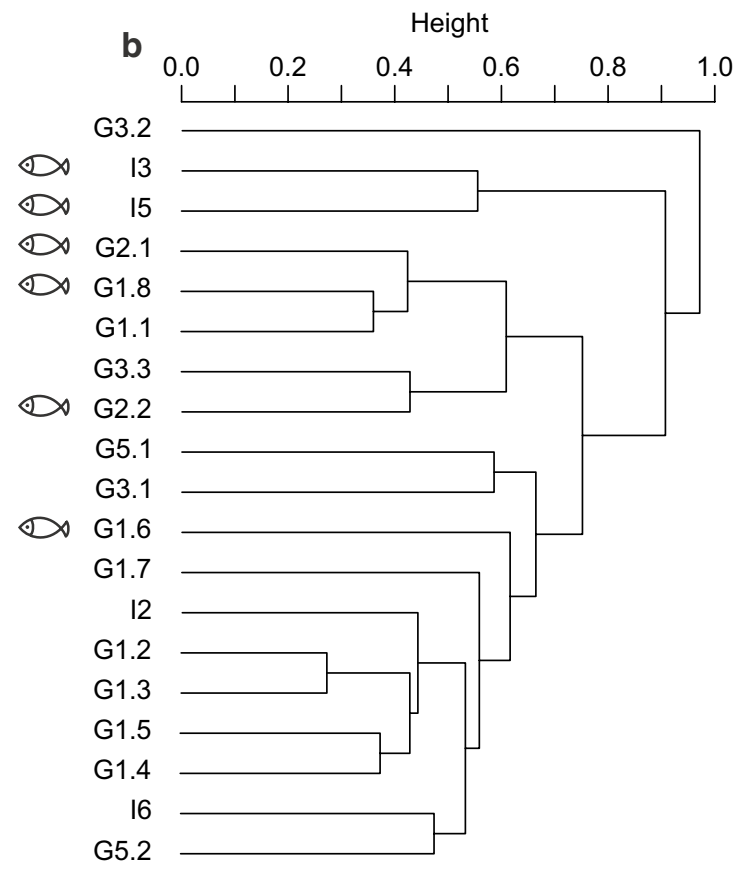

analysis. The clusters show ponds and sites that fit the analysis requirements. The fish symbols represent ponds with fish. Ponds labelled with 'I' are isolated ponds, and ponds labelled with ' $\mathrm{G}$ ' are ponds in groups

High pond density benefits poor dispersers

Dispersal is crucial for maintaining populations of aquatic invertebrates occupying relatively isolated habitats, because it facilitates the colonisation of new habitats and increases gene flows (Bilton et al. 2001). Our results show that although community similarities have large variances, adjacent ponds have higher dytiscid community similarities than distant ponds (Figs. 2, 3). This implies that increasing structural connectivity can facilitate dispersal and reduce the isolation of potentially suitable habitats for dytiscids. However, the extent to which dytiscids can benefit from high structural connectivity varies between species (Online Appendix 2). Higher structural connectivity may reduce the search time for new habitats, thus enhancing the potential of species to disperse successfully (Tischendorf and Fahrig 2000). In particular, high structural connectivity will benefit those species with weaker dispersal capacity, which rarely disperse successfully in landscapes with low structural connectivity. Also, clustered ponds may have more similar environmental conditions than isolated 

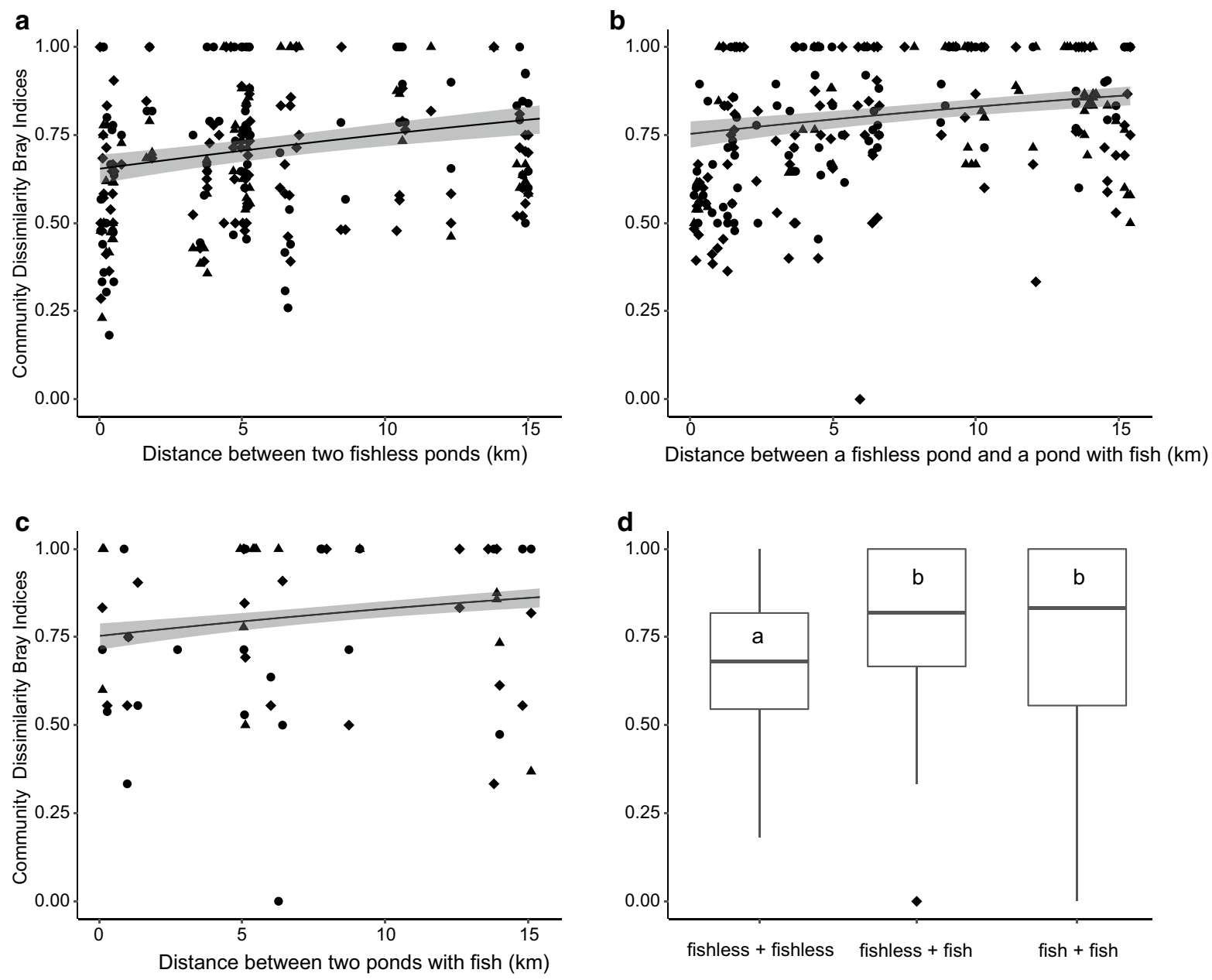

Fig. 3 Dytiscid community dissimilarity index increases with distance a between two fishless ponds, b between a fishless pond and a pond with fish, $\mathbf{c}$ between two ponds with fish. d Dytiscid community dissimilarity index is lower between fishless ponds than between the other two pond combinations. The

ponds, which may help species with limited flight capacity to find suitable new habitats nearby and establish a new population within a cluster of ponds, and subsequently to other ponds in different directions from the cluster.

Through its impact on dispersal, structural connectivity can affect the diversity of many aquatic taxa both at the local level and at the landscape level. These taxa include aquatic amphibians (e.g. Semlitsch 2000; Ribeiro et al. 2011), reptiles (Pereira et al. 2011), invertebrates (e.g. Gledhill et al. 2008), and macrophytes (e.g. Linton and Goulder 2003). Our finding that more dytiscid species are shared between

triangles represent community dissimilarities between ponds in 2017, the diamonds 2018, and the solid circles 2019. The letters in $\mathbf{d}$ represent significant differences between pond combinations, while the same letter indicates no significance between the scenarios

clustered ponds than between isolated ponds (Figs. 2, 3) indicates that structural connectivity is beneficial in facilitating successful dispersal and improving the functioning of ponds with regard to dispersal. Structural connectivity can be enhanced by increasing the provision of ponds, creating a 'pondscape' of suitable habitats (Gledhill et al. 2008; Hill et al. 2017).

In a given landscape, however, the same level of structural connectivity may constitute different levels of functional connectivity to different taxa or species. We found that species that are poor fliers, such as Graphoderus spp., are scarcely distributed in the landscape with co-occurrence only between ponds 
less than $1 \mathrm{~km}$ apart, while strong-flying species, such as Hydaticus seminiger, are more widely distributed across the same landscape (Online Appendix 1). In the conservation literature, structural connectivity is often misinterpreted as an equivalent of functional connectivity (Taylor et al. 2006; Ribeiro et al. 2011). Our study demonstrates that functional connectivity is species-specific. Similarly, Gledhill et al. (2008) found that pond density has the largest effect on the species richness of aquatic invertebrates at the radius of $1000 \mathrm{~m}$, while it has significant effects on aquatic plants already at a radius of $250 \mathrm{~m}$.

Species traits determine functional connectivity of urban ponds for dytiscids

Functional connectivity depends on behavioural responses of organisms to changes in the landscape structure (Taylor et al. 2006), which are affected by a mixture of biotic and abiotic factors that determine "gap-crossing ability" of organisms (Tischendorf and Fahrig 2000). In our study, strong dispersers, such as Acilius canaliculatus, occur in ponds across the whole landscape, while poor-flying species, such as Hyphydrus ovatus (Jackson 1972) and Graphoderus spp. (Lundkvist et al. 2002), appeared mostly in multiple ponds within the same sites (Online Appendix 1). Thus, ponds that are clustered have higher functional connectivity than isolated ponds for species with limited dispersal capacity.

Although many dytiscid species are capable of dispersing several kilometres (Lundkvist et al. 2002; Matsushima and Yokoi 2020), urban landscapes contain dispersal barriers (Johnson and Munshi-South 2017). According to our results, ponds that are distant from each other share few dytiscid species and strong dispersers are more likely to occur in isolated ponds than poor dispersers (Fig. 3 \& Online Appendix 2). We have previously demonstrated a negative response of species richness to the increasing cover of impermeable surfaces in pond surroundings (Liao et al. 2020), which suggests a negative response to decreasing structural connectivity. It is also highly likely that aquatic insects, such as dytiscids, encounter more ecological traps in more urbanized landscapes than in forested or agricultural landscapes. These ecological traps include artificial surfaces, such as vehicle windows and roofs (Nilsson 1997; Horváth et al. 2009), which can polarize $95-100 \%$ reflected light. By contrast, natural water bodies polarize only 30-80\% reflected light (Robertson et al. 2017). Such ecological traps can reduce functional connectivity for aquatic insects by increasing search time during dispersal and exposing disorientated insects to danger, such as predation and reproductive failure, which can result in population declines and even extirpation (Horváth et al. 2009). Therefore, when managing habitat for the diversity of aquatic organisms such as dytiscids, in addition to habitat quality in focal habitats, it is also essential to consider the role of secondary habitats, such as terrestrial habitats for some species to overwinter out of water, and their level of permeability.

Predators may decrease pond functioning for biodiversity

Predation is the primary regulator of a prey population (Schowalter 2016). Fish are known to modify the community composition of aquatic invertebrates (Wittwer et al. 2010; Liao et al. 2020). In ponds with fish, the decreasing abundance in most taxa is due to both direct and indirect effects of predators: Fish reduce the diversity of aquatic invertebrates, including dytiscids, via direct consumption (Laufer et al. 2009; Mendoza et al 2012), and also cause predation-induced dispersal and the decreasing availability of food (Dahl and Greenberg 1999). The weights of direct and indirect effects of predators vary among different aquatic invertebrate taxa. Dahl and Greenberg (1999) found that dytiscid abundance was greatly reduced due to direct consumption by brown trout (Salmo trutta), while predation-induced dispersal also partially contributed to the low abundance of dytiscids. In this study, we found that the presence of fish can lead to high community dissimilarities between ponds (Fig. 3d; Online Appendix 2), even within the same site (Fig. 2). We consider that the high community dissimilarity between a pond with fish and a pond without is due to the vulnerability of some dytiscid species to fish predation, especially small-sized species, such as Hydrophorus spp. (Liao et al. 2020), even though the dispersal capacity of such species enables them to access these ponds. Fish, thus, may decrease ponds' capacity to support species.

As many species of dytiscid have a poor capacity of co-existing with fish (Culler et al. 2014; Liao 
et al. 2020), ponds with fish may become sink-habitats, especially when a pond lacks habitat heterogeneity. The high variation in community dissimilarity between ponds with fish (Fig. 3d; Online Appendices 2 and 3) suggests that predation has filtered dytiscid species. Medium to large-sized species are more likely to occur in ponds with fish than smallsized dytiscids, because of their anti-predator defence mechanisms (Dettner 2014). The availability of prey refuges, however, can ease predation pressure and increase the survival of vulnerable species (Donelan et al. 2017; Ghosh et al. 2017; Liao et al. unpublished data). Emergent plants as spatial prey refuges can enhance dytiscid species richness and abundance, and also facilitate the co-existence of predator and prey species (Liao et al. unpublished data). Adequate provision of ponds with prey refuges and clusters of ponds, can therefore enhance the diversity of the urban fauna.

\section{Conclusion: supporting urban aquatic biodiversity}

This research is one of the first studies that investigates how aquatic organisms that use aerial dispersal respond to landscape connectivity. In common with terrestrial organisms and aquatic organisms dispersing with terrestrial routes, aquatic species using aerial dispersal are more likely to disperse and colonise successfully within a short distance than a long distance in urban landscapes. Changes in both abiotic (e.g. habitat isolation) and biotic (e.g. introducing fish for recreational purposes) environmental factors can affect behavioural responses of organisms. To support aquatic invertebrate diversity in urban landscapes, we recommend:

1. supplementing pond networks by increasing pond density in urban landscapes to reduce isolation of wetland habitats;

2. maintaining or creating multiple ponds at the same sites to facilitate dispersal between ponds serving as stepping ponds or extra habitats, especially for species with limited dispersal capacity;

3. retaining fishless ponds to conserve predatorintolerant invertebrates and maintain structural connectivity of ponds and functional connectivity to species.
Acknowledgements Our research was supported by Chinese Scholarship Council (Grant 201707960009 to WL). We would like to thank Aleksi Lehikoinen, Janne Soininen, and Rose Thorogood for their constructive comments on this manuscript.

Author contributions WL designed the study, collected and analysed the data, and led the writing. SV and JN revised the manuscript critically for important intellectual contents and structure. All authors gave final approval for publication.

Funding Open Access funding provided by University of Helsinki including Helsinki University Central Hospital. Funding was provided by China Scholarship Council (Grant Number 201707960009).

Data availability The data used in this study is available on http://urn.fi/urn:nbn:fi:att: 9b80433a-7890 -4771 -9586 -1317 cdef166e.

\section{Declarations}

Conflict of interest The authors declare no conflict of interests.

Open Access This article is licensed under a Creative Commons Attribution 4.0 International License, which permits use, sharing, adaptation, distribution and reproduction in any medium or format, as long as you give appropriate credit to the original author(s) and the source, provide a link to the Creative Commons licence, and indicate if changes were made. The images or other third party material in this article are included in the article's Creative Commons licence, unless indicated otherwise in a credit line to the material. If material is not included in the article's Creative Commons licence and your intended use is not permitted by statutory regulation or exceeds the permitted use, you will need to obtain permission directly from the copyright holder. To view a copy of this licence, visit http://creativecommons.org/licenses/by/4.0/.

\section{References}

Becerra-Jurado G, Foster G, Harrington R, Kelly-Quinn M (2014) Integrated constructed wetlands: hotspots for freshwater coleopteran diversity in the landscape of Ireland. Biol Environ 114(3):271-279.

Bilton DT (2014) Dispersal in dytiscidae. In: Yee D (ed) Ecology, systematics, and the natural history of predaceous diving beetles (Coleoptera: Dytiscidae). Springer, Dordrecht, pp 387-407

Bilton DT, Freeland JR, Okamura B (2001) Dispersal in freshwater invertebrates. Annu Rev Ecol Syst 32(1):159-181.

Bilton DT, Mcabendroth L, Bedford A, Ramsay PM (2006) How wide to cast the net? Cross-taxon congruence of species richness, community similarity and indicator taxa in ponds. Freshw Biol 51(3):578-590.

Brooks ME, Kristensen K, van Benthem KJ, Magnusson A, Berg CW, Nielsen A, Skaug HJ, Machler M, Bolker BM (2017) glmmTMB balances speed and flexibility among 
packages for zero-inflated generalized linear mixed modeling. R J 9:378-400

Clobert J, Le Galliard JF, Cote J, Meylan S, Massot M (2009) Informed dispersal, heterogeneity in animal dispersal syndromes and the dynamics of spatially structured populations. Ecol Lett 12(3):197-209.

Concepción ED, Moretti M, Altermatt F, Nobis MP, Obrist MK (2015) Impacts of urbanisation on biodiversity: the role of species mobility, degree of specialisation and spatial scale. Oikos 124(12):1571-1582.

Culler LE, Ohba SY, Crumrine P (2014) Predator-prey interactions of dytiscids. In: Yee D (ed) Ecology, systematics, and the natural history of predaceous diving beetles (Coleoptera: Dytiscidae). Springer, Dordrecht, pp 363-386

Dahl J, Greenberg L (1999) Effects of prey dispersal on predator-prey interactions in streams. Freshw Biol 41(4):771-780.

de Mendoza G, Rico E, Catalan J (2012) Predation by introduced fish constrains the thermal distribution of aquatic Coleoptera in mountain lakes. Freshw Biol 57(4):803-814.

Dettner K (2014) Chemical ecology and biochemistry of Dytiscidae. In: Yee D (ed) Ecology, systematics, and the natural history of predaceous diving beetles (Coleoptera: Dytiscidae). Springer, Dordrecht, pp 235-306

Donelan SC, Grabowski JH, Trussell GC (2017) Refuge quality impacts the strength of nonconsumptive effects on prey. Ecology 98(2):403-411.

Elmberg J, Nummi P, Pöysä H, Sjöberg K (1992) Do intruding predators and trap position affect the reliability of catches in activity traps? Hydrobiologia 239:187-193.

Gledhill DG, James P, Davies DH (2008) Pond density as a determinant of aquatic species richness in an urban landscape. Landsc Ecol 23(10):1219-1230.

Goertzen D, Suhling F (2013) Promoting dragonfly diversity in cities: major determinants and implications for urban pond design. J Insect Conserv 17:399-409.

Ghosh J, Sahoo B, Poria S (2017) Prey-predator dynamics with prey refuge providing additional food to predator. Chaos Solitons Fractals 96:110-119.

Hill MJ, Biggs J, Thornhill I, Briers RA, Gledhill DG, White JC et al (2017) Urban ponds as an aquatic biodiversity resource in modified landscapes. Glob Change Biol 23(3):986-999.

Horváth G, Kriska G, Malik P, Robertson B (2009) Polarized light pollution: a new kind of ecological photopollution. Front Ecol Environ 7(6):317-325.

Iversen LL, Rannap R, Thomsen PF, Kielgast J, Sand-Jensen K (2013) How do low dispersal species establish large range sizes? The case of the water beetle Graphoderus bilineatus. Ecography 36(7):770-777.

Iversen LL, Rannap R, Briggs L, Sand-Jensen K (2017) Timerestricted flight ability influences dispersal and colonization rates in a group of freshwater beetles. Ecol Evol $7(3): 824-830$.

Jackson DJ (1952) Observations on the capacity for flight of water beetles. Proc R Entomol Soc Lond Ser A 27:57-70.

Jackson DJ (1956a) Dimorphism of the metasternal wings in Agabus raffraryi Sharp and A. labiatus Brahm (COL.,
Dytiscidae) and its relation to capacity for flight. Proc $\mathrm{R}$ Entomol Soc Lond Ser A 31:1-11

Jackson DJ (1956b) Observations on flying and flightless water beetles. Zool J Linn Soc 43(289):18-42.

Jackson DJ (1972) Dispersal of Hyphydrus ovatus L. (Coleoptera, Dytiscidae). Entomol Mon Mag 108:102-104

Johnson MTJ, Munshi-South J (2017) Evolution of life in urban environments. Science 358(6363):eaam8327

Kehl S, Dettner K (2007) Flugfähigkeit der in Deutschland vorkommenden adephagen Wasserkäfer (Coleoptera, Hydradephaga). Entomologie Heute 19:141-161

Kindlmann P, Burel F (2008) Connectivity measures: a review. Landsc Ecol 23(8):879-890.

Laufer G, Arim M, Loureiro M, Piñeiro-Guerra JM, ClavijoBaquet S, Fagúndez C (2009) Diet of four annual killifishes: an intra and interspecific comparison. Neotrop Ichthyol 7:77-86.

Liao W (2017) Jakomäki-Vaarala and Fazerila Wetlands. http:// hdl.handle.net/10138/306298

Liao W, Venn S, Niemelä J (2020) Environmental determinants of diving beetle assemblages (Coleoptera: Dytiscidae) in an urban landscape. Biodivers Conserv 29(7):2343-2359.

Linton S, Goulder R (2003) Species richness of aquatic macrophytes in ponds related to number of species in neighbouring water bodies. Arch Hydrobiol 157(4):555-565.

Lundkvist E, Landin J, Karlsson F (2002) Dispersing diving beetles (Dytiscidae) in agricultural and urban landscapes in south-eastern Sweden. Ann Zool Fenn 39:109-123

Matsushima R, Yokoi T (2020) Flight capacities of three species of diving beetles (Coleoptera: Dytiscidae) estimated in a flight mill. Aquatic Insects 41(4):332-338.

Mazgajska J (1996) Distribution of amphibians in urban water bodies (Warsaw agglomeration, Poland). Ekologia Polska 44(3):245-257

Moilanen A, Hanski I (1998) Metapopulation dynamics: effects of habitat quality and landscape structure. Ecology 79(7):2503-2515.

Muñoz PT, Torres FP, Megías AG (2015) Effects of roads on insects: a review. Biodivers Conserv 24(3):659-682.

Murray CG, Kasel S, Loyn RH, Hepworth G, Hamilton (2013) Waterbird use of artificial wetlands in an Australian urban landscape. Hydrobiologia 716(1):131-146.

Nilsson AN (1997) On flying Hydroporus and the attraction of H. incognitus to red car roofs. Latissimus 9:12-16

Nilsson AN, Hájek J (2021) A world catalogue of the family Dytiscidae, or the diving beetles (Coleoptera, Adephaga). Version 1. I. 2021.

Nilsson AN, Holmen M (1995) The Aquatic Adephaga (Coleoptera) of the Fennoscandia and Denmark. Ii. Dytiscidae: II-Dytiscidea. Brill.

Oksanen J, Blanchet J, Friendly M, Kindt R, Legendre P, McGlinn D, Minchin PR, O’Hara RB, Simpson GL, Solymos P, Stevens MH, Szoecs E, Wagner H (2019) vegan: Community Ecology Package. R package version 2.5-6. https://CRAN.R-project.org/package=vegan

Pereira M, Segurado P, Neves N (2011) Using spatial network structure in landscape management and planning: a case study with pond turtles. Landsc Urban Plan 100:67-76.

Pringle C (2006) Hydrologic connectivity: a neglected dimension of conservation biology. In: Crooks M, Catherin P, 
Kevin R (eds) Connectivity conservation. Cambridge University Press, Cambridge

R Core Team (2020) R: a language and environment for statistical computing. R Foundation for Statistical Computing, Vienna, Austria. https://www.R-project.org/

Ribeiro R, Carretero MA, Sillero N, Alarcos G, Ortiz-Santaliestra M, Lizana M, Llorente GA (2011) The pond network: can structural connectivity reflect on (amphibian) biodiversity patterns? Landsc Ecol 26(5):673-682.

Robertson BA, Campbell DR, Durovich C, Hetterich I, Les J, Horváth G (2017) The interface of ecological novelty and behavioral context in the formation of ecological traps. Behav Ecol 28(4):1166-1175.

Semlitsch RD (2000) Principles for management of aquaticbreeding amphibians. J Wildl Manag 64:615-631.

Schowalter TD (2016) Insect ecology: an ecosystem approach. Academic Press, Cambridge

Smithson M, Verkuilen J (2006) A better lemon squeezer? Maximum-likelihood regression with beta-distributed dependent variables. Psychol Methods 11(1):54-71

Taylor PD, Fahrig L, Henein K, Merriam G (1993) Connectivity is a vital element of landscape structure. Oikos 68:571-573.
Taylor PD, Fahrig L, With KA (2006) Landscape connectivity: a return to the basics. In: Crooks KR, Sanjayan M (eds) Connectivity conservation. Cambridge Press, Cambridge

Tischendorf L, Fahrig L (2000) On the usage and measurement of landscape connectivity. Oikos 90(1):7-19.

The City of Helsinki Map Service (2019) Map set (Metropolitan region). https://kartta.hel.fi/. Accessed $28 \mathrm{Apr}$ 2020.

Villalobos-Jimenez G, Dunn A, Hassall C (2016) Dragonflies and damselflies (Odonata) in urban ecosystems: a review. Eur J Entomol 113:217-232

Wittwer T, Sahlén G, Suhling F (2010) Does one community shape the other? Dragonflies and fish in Swedish lakes. Insect Conserv Divers 3(2):124-133.

Zuur AF, Ieno EN (2016) A protocol for conducting and presenting results of regression-type analyses. Methods Ecol Evol 7(6):636-645.

Publisher's Note Springer Nature remains neutral with regard to jurisdictional claims in published maps and institutional affiliations. 